\title{
Maxillofacial surgery and its legal responsibilities
}

\author{
A. Béry ${ }^{1,2,4}$, Y. Soyer ${ }^{1,3,4}$ \\ 1 Specialist in dentofacial orthopedics \\ 2 DSO, Doctorate in law, Doctorate in care ethics, Honorary University lecturer at Paris VII \\ 3 Masters in health law, University Hospital Assistant, Paris VII \\ ${ }^{4}$ Expert at the Paris Court of Appeal
}

\section{ABSTRACT}

From a few simple questions are reminded the notion of medical contract within maxillofacial surgery, the obligations charged to the practitioner in particular with regard to information and informed consent of the patient. The specifics of cosmetic surgery and the situation of minors are also discussed.

\section{KEYWORDS}

Professional liability, care agreement, consent

\section{INTRODUCTION}

\begin{abstract}
"Since people are unaware, they would not know how to recognize the diseases from which they suffer, how they occur, how they end, or how they are elevated or attenuated. However, it becomes easier when the information comes from the mouth of a professional, especially since there is nothing that we can remember better than what we have suffered." Even in his epoch, Hippocrates already stressed the need to inform patients.
\end{abstract}

In the second half of the $20^{\text {th }}$ century, the obligation to provide information was gradually imposed in health law, both as a result of changes in the doctor-patient relationship and due to the evolution of medical knowledge. The concept of informed consent is part of the validity criterion of the care contract. Thus, it seems necessary to respond to some essential questions concerning maxillofacial surgery. 


\section{WHAT ARE THE TYPES OF MEDICAL CONTRACTS?}

A civil contract is so-called because the practice of medicine constitutes a liberal profession. As a result, this contract remains within the jurisdiction of civil courts.

A synallagmatic contract gives rise to reciprocal and interdependent obligations between parties. In the event of non-performance by one of the parties, the other party may refuse to perform its role.

A concluded intuitu personae is concluded according to the quality of the practitioner's work and the faith that the patient has in them. Jurisprudence dictates that the practitioner must personally fulfil their obligations. Some authors provide justification for a medical contract that is freely terminable by the intuitu personae who controls this contract. Lack of trust constitutes just cause for a break in relations.

An onerous contract, (C. Civic Art $1106)$ is one in which each party expects to derive an advantage from the contract. Therefore, it stands to reason that the practitioner must be remunerated for their performance. However, free care does not preclude the existence of contractual relationships between the practitioner and the patient.

A consensual contract is perfect because of the exchange of consent and is not subject to any form of validity. There is no legal obligation to draw up a contract of care and a fortiori to sign it. However, it should be known that this serves as proof that the patient is informed and provides consent.

\section{WHAT MAKES A CONTRACT VALID?}

According to article 1108 of the Civil Code, four conditions are essential for the validity of a contract:

- The obligatory consent of the party;

- Their capacity to the contract;

- Subject matter of the undertaking;
- A cause that justifies the undertaking.

As a consequence, a lack of consent nullifies the contract of care. The same shall apply if a minor or a disabled person, acting alone, gives their consent to receive care.

\section{WHAT ARE THE PRACTITIONER'S OBLIGATIONS?}

Under French law, there are two types of contractual obligation: an obligation of means and an obligation of result. In oral medicine, only the design and manufacture of prosthetics are subject to an obligation of result. It must also be pointed out that a certain number of obligations of means tend to shift toward obligations of results. These include the following: security, conformity, material vigilance, waste, sterilization, satisfaction and improvement, therapeutic follow-up, and information. 


\section{IS THERE A LINK BETWEEN COSMETIC SURGERY AND AN OBLIGATION OF RESULT?}

Cosmetic surgery usually indicates an obligation of means, which are called reinforced means. This is characterized by the rule of proportionality between the risk of intervention and the significance of the defect. With smaller defects, less invasive treatment is required and less means are required to ensure the patient's safety.

The Court of Cassation's judgment of November $1^{\text {st }} 1992$ states that
"The Court held that no fault could be attributed to the cosmetic surgeon following the placement of two breast implants. The disappointing result was due to the method itself, which remains statistically random and that the patient's decision was well reasoned. Let us not forget that once a cosmetic procedure is performed to completion, it is subject to VAT."

\section{WHEN CAN A SHARED RESPONSIBILITY BE EVOKED?}

We would like to touch on liability in solidum. We take as an example the case of an orthodontist who made an (erroneous) recommendation for canine extraction and that of the respective dental surgeon who has the capacity to perform surgical procedures and proceeds with the surgery.
The surgeon's liability is retained because he/she should have confirmed the prescription.

As soon as there is a new practitioner, the patient falls under a new contract of care. This is what happens with treatment by orthognathic surgeons.

\section{SHOULD MULTIPLE REFERENCES BE GIVEN?}

In case of treatment with orthognathic surgery, it seems logical for us to think (after an accident during the procedure or with a poorly confirmed result) that if it were possible to choose another practitioner, these difficulties could have been avoided. We therefore consider that the patient is unlucky. In this case, if the patient deems it desirable to have two other practitioners as references, the role of the orthodontist is to advise the patient and then it is then up to the patient to make a choice. However, there is one restriction; it is advisable to consider how far away the surgeon is from the surgeon. 


\section{WHO MUST INFORM THE PATIENT?}

L.1111-2 public health code (c.s.p.):

"This information is the responsibility of all health professionals in accordance with their authority and with the professional rules applicable to them. It can only be dispensed with in urgent cases or instances where informing may be impossible. This

\section{WHEN MUST THEY BE INFORMED?}

The patient participates in the decision-making concerning their health.

L.1111-4 c.s.p.: "Everyone including the health professional must consider the information provided and recommendations given when making health-related decisions. The physician must respect the patient's will after having informed them of the consequences of their choices."

However, the patient's decision is not a command; the practitioner still has the right to refuse to comply. It is so easy to say "In your case, I do not know what to do..."

\section{WHAT INFORMATION MUST BE GIVEN?}

L.1111-2, c.s.p.: "Everyone has the right to be informed about the state of their health. This information concerns various investigations, treatments, or preventive actions that are proposed, their usefulness, their possible urgency, their consequences, the normally predictable frequent or serious risks entailed as well as other possible solutions and information is delivered during oneon-one interviews with the patient." We must remember that since January $25^{\text {th }}$, dental assistants are now considered health professionals. Nevertheless, they are only authorized to relay the information previously provided by the practitioner.

It is fundamental to remember L.1111-2, c.s.p., which states "The rights of minors or adults under guardianship are exercised by those with parental authority or by the guardian. The persons concerned have the right to receive information and to take part in the decision-making process in a manner appropriate either to the degree of maturity in the case of minors or to their ability to use their power of discernment in case of adults under guardianship."

Consequently, it is not feasible to present the treatment plan without the presence of one or more parents.

the foreseeable consequences in case of refusal." Let us emphasize here the need to inform the patient about other therapeutic possibilities. To this end, the practitioner is professionally liable for any breach in the duty of providing information. The dental surgeon who did not inform their patient of the potential risks of dental fractures inherent to 
or related to this pathology and thus denied the patient the choice of early orthodontic treatment will be held accountable for damages incurred.
In addition, the information must be more reliable and meticulous as the patient is fragile

\section{HOW SHOULD INFORMATION BE PROVIDED?}

According to L.1111-2, c.s.p., "In the event of a legal dispute, it is the duty of the professional or healthcare establishment to provide proof that the information has been issued to the person concerned under the conditions outlined in this article.
This evidence may be provided by any means." In such an instance, drafting a signed contract of care is invaluable. If one can provide proof by any means, the first gesture is to make a note of it in the medical record.

\section{HOW IS THE NOTION OF CONSENT ANALYZED?}

Informed consent can only be obtained when the patient has received sufficient information.

Nonetheless, the first consent evidently comes from the practitioner:

Article R4127-232 formerly (art. 28 C. ethics): "Except in cases of emergency and in the event of failure to fulfil humanitarian duties, the dental surgeon is always entitled to refuse care for personal or professional reasons provided that (1) it causes no harm to the patient and (2) the continuity of care is assured and all useful information is provided." The dental surgeon can only exercise this right in compliance with the rules set forth in article 8. "Knowing when not to provide treatment is of course a good way to avoid litigation." As for the patient's consent, L.1111-4, c.s.p, "No medical procedure or treatment may be practiced without the free and informed consent of the person, and such consent may be withdrawn at any time." Above all, "The consent of the minor or adult under guardianship must be systematically sought to afford the ability to express their will and participate in the decision."

If the minor now has the right, according to Article L.1111-2 paragraph 5 c.s.p., to receive information and to participate in decision-making in a manner appropriate to their level of maturity, consent is required from those possessing parental authority.

"Parents involve the child in decisions that affect them, depending on their age and maturity." Thus, it is only the minor's participation that is sought, and as such, parental consent, though required, only has legal value.

If the patient or their beneficiary agrees to a therapeutic procedure with orthognathic surgery, informed consent must be renewed with the surgeon. 


\section{CONCLUSION}

Jurisprudence does not control the law. It is therefore necessary to be very attentive to the decisions made by judges regarding the lack of information often mentioned for patients attracted by the prospect of compensation, particularly as it is with this breakdown in communication that litigation begins.

The healthcare professional will therefore take special care regarding the documentation of any medical file in which the details of each interview will be disclosed.
This information should be constant and regular throughout the contract of care.

It should be remembered that the information should be communicated to the patient in terms that can be easily understood and with a minimum used of technical jargon.

Conflicts of interest: The authors declare that they have no conflicts of interest.

\section{BIBLIOGRAPHY}

1. Bery A. Le contrat de soins. Paris : SID, 1997.

2. Bery A, Delprat L. Droit et obligations du chirurgien-dentiste. Paris : Puits Fleury, 2006.

3. Bery A, Cantaloube D, Delprat L. Expertise dentaire et maxillo-faciale. EDP Sciences, 2010.

4. Labyt-Leroy A-S. Les Chirurgiens-Dentistes et la médecine bucco-dentaire à visée esthétique : injection d'acide hyaluronique et responsabilité. Droit et Médecine Bucco-Dentaire 2011;1:201-204.

5. Levigne P. Responsabilités professionnelles dans le cadre de soins dispensés aux mineurs. Rev Orthop Dento Faciale 2009;43:449-457.

6. Simonet P, Missika P, Pommarede P. Recommandations de bonnes pratiques en odonto-stomatologie. Paris: Espace ID, 2015. 